\title{
Do Non-recurring Gains and Losses Affect Analyst Behavior?
}

\author{
Song Yifeng \\ Tsinghua University \\ Chen Zhanguang \\ Tsinghua University \\ Liang Tian \\ Renmin University \\ Wang Qiaowan \\ Tsinghua University
}

Based on a sample of A-share listed companies from 2009 to 2015, this paper studies the non-recurring gains and losses of China's unique indicators. The article finds: (1) the proportion of non-recurring profit and loss of corporate analysts tracking and reporting is relatively small, negatively correlated. (2) Companies with large non-recurring gains and losses, analysts predict more inaccurate, less optimistic deviations, larger forecast ranges. This paper has deepened the understanding of the impact of nonrecurring gains and losses on the capital market, enriching the literature on non-recurring gains and losses and analyst behavior, which is of great significance to both theory and practice.

Keywords: non-recurring gains and losses, analyst tracking, analyst forecasts

\section{INTRODUCTION}

The China Securities Regulatory Commission for the first time put forward the concept of "nonrecurring profit and loss" in 1999, the China Securities Regulatory Commission in 2001 issued the "Q\&A No.1 on Information Disclosure Regulations for Companies Offering Their Securities to the PublicExtraordinary Profit and Loss" this document has made a more clear definition, the China Securities Regulatory Commission revised parts of this document in 2004, in 2007, the accounting standards and guidelines began to be implemented within the scope of listed companies, the China Securities Regulatory Commission once again revised the non-recurring gains and losses. However, the requirement for disclosure of non-recurring gains and losses was in 2008, the China Securities Regulatory Commission revised "Q\&A No.1 on Information Disclosure Regulations for Companies Offering Their Securities to the Public-Extraordinary Profit and Loss"again. It was renamed as "Interpretative Announcement on Information Disclosure of Companies Publicly Offering Securities". This document stipulates that listed companies shall execute from December 1, 2008. When preparing the 2008 annual financial report, it 
shall disclose the non-recurring gains and losses in accordance with the requirements of this announcement. The planned listed company shall execute from the date of the announcement. The document stipulates that the listed company shall start from December 1, 2008, disclose non-recurring profits and losses in the preparation of 2008 annual financial report in accordance with the requirements of this announcement, and the proposed listed company start execute this document from the date of announcement.

Non-recurring gains and losses refer to items that are not directly related to the company's normal operating activities, and although they related to normal operating activities, due to their special nature and occasional nature, they affect the users of financial report to make normal judgments on the company's business performance and profitability. From the view of definition, non-recurring gains and losses are contingent, and it is not directly related to the normal operating activities of companies. From the items of non-recurring gains and losses, it includes twenty-one items, such as the disposal of illiquid assets, non-monetary assets exchange profit and loss items and so on. Non-recurring profit and loss due to it is not represent to the behavior of the company's main business.

Therefore, it is generally excluded when considering financing decisions, such as the requirements of initial public offering in recent three fiscal year net profit is positive and accumulated more than 30 million yuan, the calculation of net profit is based on the lower one before and after deducting the nonrecurring profit and loss; when issuing additional shares to the public, the listed company is required to make continuous profits in the last three accounting years. The net profit after deducting the non-recurring profit and loss is calculated on the basis of the lower one. There are also corresponding regulations when the listed companies allocate shares and issue convertible bonds. From the regulation, it can be found that the non-recurring profit and loss plays an important role in the company's financing process.

In the existing literature, some scholars have discussed the recognition of non-recurring gains and losses and how to disclose them. By analyzing the proportion of non-recurring gains and losses of listed companies, the regulatory authorities are suggested to put forward requirements for non-recurring gains and losses disclosure as soon as possible (Meng and Zhang, 2003). According to the changes of nonrecurring profit and loss disclosure rules from 2001 to 2007, Yan(2008) examined the changes of enterprise asset impairment provisions, and pointed out that the strengthening of disclosure rules is conducive to restricting the earnings management of listed companies. Zhou and Zhou (2005) found that the main business was still the main business of listed companies, and the increase of non-recurring profits and losses did not affect the overall performance of enterprises, but they found that some companies used non-recurring profits and losses to adjust corporate profits. Xu (2012) found that listed companies could only make use of non-recurring gains and losses to turn losses into profits, but only play a moderating effect. Tao et al. (2007) described in more details the role of non-recurring gains and losses in loss-making companies and high-profit companies, and found that the role of loss-making companies is consistent with the findings of previous scholars-both use non-recurring Profit and loss are the motives for turning losses into profits, but for high-profit companies, non-recurring gains and losses have the function of smoothing profits and stabilizing stock prices [5]. This role has not been found by scholars in the past.

Analysts in the capital market play an important role. As a financial intermediary, analysts mainly undertake the functions of information interpretation and transmission. For example, analysts need to issue research reports. The research reports not only analyze the enterprises, but also make predictions. They provide assistance to investors in decision-making. Gong and $\mathrm{Yu}$ (2017) found that the forecast of management performance has information content, which can influence the range of analysts' forecast correction and thus reduce the deviation of analysts' forecast. Liu and Gao (2014) found that analysts' forecasts are not only affected by information quality, but also it can be influenced by analysts' industry expertise. Experienced analysts make more accurate forecasts, and the source of information is also a concern of scholars. From the perspective of supply chain, Li et al. (2018) found that Shared auditors not only have audit supervision function, but also serve as a channel for information transmission, thus reducing the analyst's prediction deviation. In recent years, with the realization of short selling mechanism of margin selling and short selling, Huang (2018) found that short selling mechanism is 
conducive to restrain management behavior, thus improving information transparency and reducing analyst prediction bias. With the prevalence of text analysis, non-financial information has attracted more and more attention from scholars. Wang et al. (2017) used text analysis to find that the disclosure of nonfinancial information in corporate annual reports is conducive to reducing analyst prediction errors and improving analyst prediction accuracy [10].

Although scholars studied the analyst's behavior from the perspectives of CSR disclosure and accounting conservatism (Ding et al., 2016). However, there are not exist scholars who have studied the impact of non-recurring gains and losses on analysts' behavior from the perspective of the accounting index of non-recurring gains and losses. Mentioned in the literature information quality is beneficial to reduce the analysts forecast errors, however, when analysts obtain enterprise information, in addition to field research (Tang and Chen, 2017), a more convenient and faster way is to view the enterprise annual report, and an important index of enterprise annual report disclosure is non-recurring profit and loss. This index measures the income unrelated to the main business of the enterprise, and it conveyed to analysts whether the enterprise is developing healthily and whether it has potential. For example, when the profit is disclosed in the annual report, the consolidated non-recurring profit and loss, the non-recurring profit and loss of the parent company and the net profit after deducting non-recurring profit and loss will be considered. However, the proportion of non-recurring profit and loss may directly affect analysts' behavior, such as tracking quantity, reporting quantity, prediction accuracy, optimistic deviation degree, forecast interval, etc. The reason is that the non-recurring profit and loss has information content as an important financial indicator, and analysts will take it as an important basis for tracking the company. If analysts track a company with a large proportion of non-recurring profit and loss, the main business of the enterprise may be bad due to the large proportion of the index. An important basis for analysts' forecast is the growth of main business. Therefore, the number of analysts to track will be reduced, and the analysts forecast accuracy, the degree of deviation and prediction intervals will be affected.

The main contributions of this paper are as follows: First of all, from the perspective of enterprise information, we find an important index of enterprise information transmission, and find that it has information content, and to a certain extent reflects the good or bad status of enterprise operation;

Second, from the perspective of analysts, we can know whether the enterprise will consider the nonrecurring profit and loss when choosing the tracking company, and how the non-recurring profit and loss affect the analyst's behavior, such as whether the analyst tracks, the number of reports issued after tracking, the accuracy of the analyst's forecast and optimistic bias, etc., and the analysts will consider the cost and benefits, thus affecting their decision-making behavior. The third is to provide important suggestions for investors to understand the financial indicators. Non-recurring profit and loss is a unique indicator in China. However, there are not many scholars studying how to make full use of this indicator and how to serve investors' decision-making. To sum up, this paper plays an important role in theory and practice.

The analyst can learn enterprises will consider when choosing tracking company non-recurring profit and loss and non-recurring profit and loss how to influence analyst behavior, such as whether analysts tracking, tracking after the report issued by number, analysts predict accuracy deviation, etc., and optimistic analysts would consider costs and benefits, thus affecting its decision-making behavior; Thirdly, it provides important suggestions for investors to understand the financial index. Non-recurrent gains and losses are unique indicators in China, but there are not many researches on how to make full use of the index and how to serve investors in decision-making. To sum up, this paper plays an important role in both theory and practice. The structure of this paper is as follows: the second part is theoretical analysis and research hypothesis; the third part is the research design; the fourth part is the empirical results and analysis; the fifth part is the conclusion of this paper.

\section{LITERATURE REVIEW AND RESEARCH HYPOTHESIS}

With the development of China's capital market, analysts play an increasingly prominent role in helping enterprises interpret financial information $(\mathrm{Qu}$ and $\mathrm{Bi}, 2016)$, and transmit the interpreted 
financial information to the capital market through reports. The role of the analyst is mainly in two aspects: The first aspect is the ability of information mining. For example, the analyst will deconstruct the financial statements to analyze the development status of the enterprise and form the forecast results for the capital market investors to use; the other is the ability to interpret information, such as the analysis of public data. Which type of factors influence analyst behavior? Many scholars have done research in this area. Wu et al. (2016) analyzed from the perspectives of rationality and irrationality, it is found that both the irrational factors of investor sentiment and the rational factors of corporate governance and information disclosure will influence the forecasting behavior of analysts. Wang et al. (2017) found that the higher the frequency of risk information disclosure, the higher the prediction accuracy of analysts. Meanwhile, analysts have heterogeneity. Compared with star analysts, non-star analysts and analysts with less industry expertise improved their prediction accuracy more significantly after the frequency of annual report risk disclosure increased. Some analysts have commercial purposes. Hu and Xia (2017) found that allowing short selling is conducive to correcting analysts' commercial purposes and improving their industry expertise. Analysts generally get information from four aspects: the financial statements of the enterprise, field research, industry indirect access and unofficial information, including enterprise financial statements are enterprise public information, analyst obtain low cost, but the enterprise financial reporting quality is affected by many factors, such as the attitude of the management and the auditor quality. Qi (2018) took audit quality as an index of the quality of corporate financial statements, and research found that audit quality influenced analysts' predictions. Hu et al. (2003) found that the overall development level of China's analysts is not high, and their dependence on corporate information is more from information in public statements, and their dependence on information channels such as research and press conferences is relatively low. $\mathrm{Hu}$ and Lin (2005) found that educational background and experience had a relatively weak influence. Educational background had a greater influence on analytical ability, while work experience had a greater influence on analytical quality. Tang and Chen (2015) found that the interest alliance with listed companies was the main motivation for related securities analysts to participate in field research. Jia et al. (2015), based on the data collected manually from the field survey of analysts from 2009 to 2012, found that after the investigation, the analyst not only improves the prediction degree of the research company, but also produces spillover effects, and the prediction accuracy of the industry is also improved, and then finds that the analyst investigation has information value. Tan and Cui (2015) found that no matter whether the analyst participated in the survey or not, the more times the target company was surveyed and the more institutions participated in the survey, the worse the forecast accuracy of the analyst and the higher the forecast optimism. Tao (2018) also found that the private information acquisition method of analyst research can improve the accuracy of analyst prediction.

From the above analysis, it can be seen that the quality of financial information represented by the financial statements of enterprises will also affect the prediction accuracy and optimism bias of analysts. Sun et al. (2013) pointed out that the evaluation of financial report quality system involves three aspects: demanders, executors and supervisors, and evaluation targets should be set according to demanders' demands [26]. It can be found that the analyst is one of the quality requirements of the company's financial report. Zhou and Zhou (2005) pointed out that non-recurring profit and loss is an important index to measure the quality of a company's profitability, and non-recurring profit and loss has an important impact on the financial performance of listed companies. Xu (2012) found that the effect of the use of non-recurring profit and loss of listed companies has a profit, but non-recurring profit and loss is a kind of regulation, the current profit and loss is still a major source of profits of listed companies, Jiang and Xiong (2012) used the non-recurring gains and losses as earnings management indicators, it is found that when the accounting policy is changed, the company will conduct earnings manipulation, ST company has the stronger motivation of earnings management. Cui et al. (2016) studied the correlation between non-recurring profits and losses of companies and the quality of their financial reports, and revealed the difference in the degree of correlation between non-recurring profits and losses of ST and non-ST companies and the quality of their financial reports through empirical tests. Sai (2017) pointed out that the larger the proportion of non-recurring gains and losses in the net profit of an enterprise, the worse 
the profit structure of the enterprise. Non-recurring gains and losses mainly include 21 items such as noncurrent assets disposal gains and losses. Dong et al. (2015) analyzed the disclosure of non-recurring profits and losses in the enterprise industry and found that quite a few enterprises used government subsidies to adjust their profits. Yang et al. (2018) found that the impact of non-recurring gains and losses on a company's performance is related to the systemic risks of the industry and the overall profit level. The greater the risk it faces, the lower the profit level, and the greater the impact of non-recurring gains and losses. Deng (2015) found that if the company's net profit contains a large proportion of nonrecurring gains and losses of a special nature and low continuity, it will cause interference or even mislead the statement users in their evaluation of the listed company's real profitability. Li and Zhang (2003) found that the accounting indicators after deducting non-recurring gains and losses have incremental information content. Zhao and Shang (2014) found that listed companies would use nonrecurring profits and losses to conduct real earnings management, so as to determine the long-term value of enterprises. Jiang and Wang (2003) explored the causes of non-recurring gains and losses and found that non-recurring gains and losses occur regularly. Fan and Zheng (2009) believed that the dynamic evaluation and embedded analysis of non-recurring gains and losses will be carried out to reasonably assess the impact of non-recurring gains and losses. Wei et al. (2007) found that non-recurring gains and losses indeed played an important role in the turnaround of listed companies and whether the subsequent years would continue to lose money, and its role was far greater than the controlling accrued profits after deducting non-recurring gains and losses. Wang and Zhang (2013) the implementation of the 06 standard, companies prefer to use non-recurring gains and losses for earnings management. According to the characteristics of analyst heterogeneity, we grouped analysts according to stars and non-stars, local analysts and overseas background analysts, and proposed the following hypothesis:

H1a: The larger the proportion of non-recurring profits and losses, the greater the risk of the enterprise may be. The more analysts can pay attention to the risk of the enterprise, thus reducing the tracking of such enterprises.

H1b: The larger the proportion of non-recurring profits and losses, the worse the corporate profit structure, the more difficult and inaccurate the analysts' earnings forecast. Meanwhile, the range and optimism of the analysts are also different.

\section{RESEARCH DESIGN}

\section{Data Sources and Selection}

In this paper, A-share listed companies from 2009 to 2015 are selected and dealt with as follows :(1) financial and insurance listed companies are excluded; (2) The listed companies that have ST during the sample period are excluded; (3) Samples with missing data are eliminated; (4) In order to avoid the influence of extreme values, in this paper, all continuous variables are winsorized processed with $1 \%$ and $99 \%$ respectively. At the same time, in order to control potential autocorrelation problems, we cluster all the standard errors of regression coefficients in the model at the enterprise level. All the control variables in this paper are from CSMAR database, among which star analysts and non-star analysts are selected by "New Fortune". 


\section{Definition of Variables}

TABLE 1

VARIABLE DEFINITION TABLE

\begin{tabular}{|c|c|}
\hline Variable name & Variable definition \\
\hline Cov_Report & $\begin{array}{l}\text { The number of analyst reports is equal to: the total number of annual analyst } \\
\text { reports, which is adjusted by taking logarithms in this paper. }\end{array}$ \\
\hline Cov_num & $\begin{array}{l}\text { The number of analysts tracked is equal to the annual summary of the number of } \\
\text { analysts tracked, which is adjusted by taking the logarithm in this paper. }\end{array}$ \\
\hline Cov_STAR & $\begin{array}{l}\text { The number of star analysts to be followed is equal to: the annual number of star analysts } \\
\text { to be followed is summarized, which is adjusted by taking logarithms in this paper. }\end{array}$ \\
\hline Cov_NonSTAR & $\begin{array}{l}\text { The number of non-star analysts to be followed is equal to: the annual number of non- } \\
\text { star analysts to be followed is summarized, which is adjusted by taking logarithms in } \\
\text { this paper. }\end{array}$ \\
\hline Cov_Foreign & $\begin{array}{l}\text { The number of overseas background analysts to be followed is equal to: the number of } \\
\text { overseas background analysts to be followed is summarized. This paper takes the } \\
\text { logarithm to adjust. }\end{array}$ \\
\hline Cov_local & $\begin{array}{l}\text { The number of analysts without overseas background is equal to: the number of analysts } \\
\text { without overseas background is summarized, which is adjusted by taking the logarithm } \\
\text { of this paper }\end{array}$ \\
\hline Facc & $\begin{array}{l}\text { Prediction accuracy, equal to: the absolute value of the difference between the EPS } \\
\text { forecast by an analyst for a certain stock in a certain year and the actual EPS of that stock in } \\
\text { that year divided by the absolute value of the actual EPS of that stock. }\end{array}$ \\
\hline Fopt & $\begin{array}{l}\text { The optimism bias is equal to the EPS of an analyst's forecast for a stock in a given year } \\
\text { minus the actual EPS of the year divided by the closing price of the stock in the previous } \\
\text { trading day. }\end{array}$ \\
\hline Horizon & $\begin{array}{l}\text { The forecast interval is equal to: the difference (number of days) between the forecast } \\
\text { time of a certain analyst in a certain year and the release date of the annual financial } \\
\text { report, which is adjusted by taking the logarithm in this paper. }\end{array}$ \\
\hline NCSKEW & Negative return skewness coefficient, as the first index of crash risk. \\
\hline DUVOL & The rate of fluctuation in earnings, which can capture asymmetric volatility in stock returns. \\
\hline EI_Per & $\begin{array}{l}\text { The proportion of non-recurring gains and losses, equal to: the proportion of non- } \\
\text { recurring gains and losses to net profit (including non-recurring gains and losses). }\end{array}$ \\
\hline EI & $\begin{array}{l}\text { Absolute value of non-recurring gains and losses is equal to: absolute value of non- } \\
\text { recurring gains and losses. }\end{array}$ \\
\hline $\mathrm{ROA}$ & Return on assets, equal to :(net income)/total assets \\
\hline TQ & Enterprise value, equal to: the market value of the company/the replacement cost of assets. \\
\hline Growth & $\begin{array}{l}\text { Growth is equal to: (sales revenue of the current year-sales revenue of the previous } \\
\text { year)/sales revenue of the previous year }\end{array}$ \\
\hline Top1 & Equity concentration, equal to: the proportion of the largest shareholder's equity \\
\hline SOE & Property right nature, equal to: state-owned enterprises $=1 ;$ Private enterprise $=0$ \\
\hline Size & $\begin{array}{l}\text { The size of the company is equal to: the total assets of the company, which is adjusted } \\
\text { by taking the logarithm in this paper. }\end{array}$ \\
\hline Leverage & Financial leverage, equal to: asset-liability ratio \\
\hline TV & Trading volume, equal to: annual stock trading volume \\
\hline Boardsize & Board size, equal to: number of board members \\
\hline Compensation & $\begin{array}{l}\text { Executive compensation is equal to: the total compensation of the top three executives, } \\
\text { which is adjusted by taking logarithm in this paper }\end{array}$ \\
\hline $\mathrm{RD}$ & $\mathrm{R} \& \mathrm{D}$ expenditure, equal to: $\mathrm{R} \& \mathrm{D}$ expenditure in sales revenue ratio \\
\hline
\end{tabular}




\section{EMPIRICAL RESULTS AND ANALYSIS}

\section{Descriptive Statistical Analysis of Variables}

Table 2 gives the descriptive statistical results of the main independent variables and dependent variables in this paper. It can be seen from the table that the logarithm of the mean (median) number of reports tracked and predicted by analysts is 3.433 (3.555), this indicates that the analysts' tracking and forecasting reports are not highly discrete. The logarithm of the mean (median) number of analysts tracked is 1.994 (1.092), indicating that the number of analysts tracking has a high degree of dispersion. The logarithm of the mean (median) number of star analysts tracking is $0.847(0.693)$. The logarithm of the mean (median) number of non-star analysts tracking is 1.995 (2.079), indicating that the number of analysts tracked is more concentrated on non-star analysts rather than star analysts. The logarithm of the mean (median) number of overseas analysts tracking is $0.220(0.000)$; the logarithm of the mean (median) number of local analysts tracking is 2.135 (2.197), indicating that the number of analysts tracking is more concentrated on local analysts rather than overseas analysts. The mean (median) of analysts forecast accuracy is $1.192(0.177)$, shows that analysts forecast accuracy of discrete degree is higher. The mean (median) of analysts predict positive deviation is 0.009 (0.003), it indicates that the dispersion degree of optimism deviation is not high and the degree of optimism deviation is not big. The mean of analysts forecasting interval is 4.979 (4.949), it indicates that the dispersion degree of the analyst's forecast interval is not large.

The mean (median) proportion of non-recurring profit and loss to net profit is $0.184(0.093)$, and the mean (median) logarithm of the absolute value of non-recurring profit and loss is 16.456 (16.414).The descriptive statistical results of the remaining control variables are shown below, which will not be introduced one by one due to limited space.

TABLE 2

\section{DESCRIPTIVE STATISTICS}

\begin{tabular}{|c|c|c|c|c|c|c|}
\hline VarName & Obs & Mean & SD & Min & Median & Max \\
\hline Cov_Reportlog & 11315 & 3.433 & 1.277 & 0.000 & 3.555 & 6.474 \\
\hline Cov_Num_log & 11172 & 1.994 & 1.092 & 0.000 & 2.079 & 4.317 \\
\hline Cov_STAR_log & 11315 & 0.847 & 0.766 & 0.000 & 0.693 & 2.944 \\
\hline Cov_NonSTAR_log & 11315 & 1.995 & 0.919 & 0.000 & 2.079 & 4.111 \\
\hline Cov_Foreign_log & 11315 & 0.220 & 0.417 & 0.000 & 0.000 & 2.565 \\
\hline Cov_Local_log & 11315 & 2.135 & 0.934 & 0.000 & 2.197 & 4.248 \\
\hline Facc & 10270 & 1.192 & 15.718 & 0.000 & 0.177 & 1499.000 \\
\hline Fopt & 10211 & 0.009 & 0.026 & -0.176 & 0.003 & 0.523 \\
\hline InHorizon & 11315 & 4.979 & 0.440 & 2.890 & 4.949 & 6.246 \\
\hline EI_Per & 11315 & 0.184 & 0.217 & -0.024 & 0.093 & 0.717 \\
\hline InAbsfeijing & 11315 & 16.456 & 1.827 & 4.900 & 16.414 & 23.572 \\
\hline ROA & 11315 & 0.049 & 0.037 & -0.010 & 0.043 & 0.130 \\
\hline TQ & 11127 & 2.589 & 1.529 & 1.045 & 2.082 & 6.737 \\
\hline Growth & 10953 & 0.168 & 0.265 & -0.241 & 0.127 & 0.840 \\
\hline Top1 & 11315 & 0.368 & 0.145 & 0.147 & 0.355 & 0.643 \\
\hline SOE & 11290 & 0.439 & 0.496 & 0.000 & 0.000 & 1.000 \\
\hline Size & 11315 & 22.072 & 1.179 & 20.314 & 21.893 & 24.559 \\
\hline Leverage & 11315 & 0.430 & 0.207 & 0.085 & 0.431 & 0.781 \\
\hline TV & 11315 & 5.745 & 3.838 & 1.026 & 4.747 & 14.761 \\
\hline Boardsize & 11277 & 8.926 & 1.791 & 0.000 & 9.000 & 18.000 \\
\hline Compensation & 11288 & 15.119 & 0.749 & 10.714 & 15.091 & 18.606 \\
\hline RD & 11315 & 0.026 & 0.029 & 0.000 & 0.018 & 0.102 \\
\hline
\end{tabular}




\section{Main Test Analysis}

In this paper, fixed-effect panel regression was carried out on the main test model (1) and (2) to verify the influence of the proportion of non-recurring profit and loss to net profit (EI_Per) on the number of analyst reports (Cov_Report_log) and the number of analysts tracking (Cov_Num_log). The regression results are shown in Table 3. In the regression model (1) on the number of analyst reports (Cov_Report_log), the coefficient of the proportion of non-recurring profit and loss to net profit (EI_Per) is negative and significant at $1 \%$, indicating that the higher the proportion of non-recurring profit and loss to net profit of an enterprise, the less the number of analysts' reports on the enterprise. In the regression model (2) on the number of analyst reports (Cov_Report_log), the coefficient of the proportion of nonrecurring profit and loss to net profit (EI_Per) is also negative and significant at $1 \%$, indicating that the higher the proportion of non-recurring profit and loss to net profit of an enterprise, the fewer analysts tracking number. By the above regression results, it can be found that the index of non-recurring gains and losses do have certain information content, and analysts are paying attention to this indicator when tracking the company. The higher the indicator, the higher the company's profitability is. The profitability of the year is not enough to explain the company's value. Therefore, the company also lacks the need for analysts to keep tracking analysis.

Cov_Report_log $=\alpha_{1}$ EI_Per $+\alpha_{2}$ ROA $+\alpha_{3}$ TQ $+\alpha_{4}$ Growth $+\alpha_{5}$ Top $1+\alpha_{6}$ SOE $+\alpha_{7}$ Size $+\alpha_{8}$ Leverage $+\alpha_{9} \mathrm{TV}+\alpha_{10}$ Boardsize $+\bar{\alpha}_{11}$ Compensation $+\alpha_{12} \mathrm{RD}+\alpha_{13}$ Year $+\alpha_{14}$ Ind $+\varepsilon$

Cov_Num_log $=\beta_{1}$ EI_Per $+\beta_{2}$ ROA $+\beta_{3}$ TQ $+\beta_{4}$ Growth $+\beta_{5}$ Top $1+\beta_{6}$ SOE $+\beta_{7}$ Size $+\beta_{8}$ Leverage $+\beta_{9} \overline{\mathrm{TV}}+\beta_{10}$ Boardsize $+\beta_{11}$ Compensation $+\beta_{12} \mathrm{RD}+\beta_{13}$ Year $+\beta_{14}$ Ind $+\varepsilon$

\section{TABLE 3}

\section{REGRESSION RESULTS OF MAIN TEST}

\begin{tabular}{|c|c|c|}
\hline \multirow{2}{*}{ Model Variable } & (1) & (2) \\
\hline & Cov_Report_log & Cov_Num log \\
\hline \multirow[t]{2}{*}{ EI_Per } & $-0.548^{* * *}$ & $-0.516^{* * *}$ \\
\hline & $(-13.12)$ & $(-14.21)$ \\
\hline \multirow[t]{2}{*}{$\mathrm{ROA}$} & $9.191^{* *}$ & $7.461^{* * *}$ \\
\hline & $(25.88)$ & $(24.23)$ \\
\hline \multirow[t]{2}{*}{ TQ } & $0.150^{* * *}$ & $0.134^{* * *}$ \\
\hline & (15.53) & $(15.91)$ \\
\hline \multirow[t]{2}{*}{ Growth } & $0.084^{* *}$ & 0.014 \\
\hline & $(2.58)$ & $(0.48)$ \\
\hline \multirow[t]{2}{*}{ Top1 } & -0.148 & -0.135 \\
\hline & $(-1.47)$ & $(-1.54)$ \\
\hline \multirow[t]{2}{*}{ SOE } & $-0.340^{* * *}$ & $-0.281^{* * *}$ \\
\hline & $(-9.52)$ & $(-9.00)$ \\
\hline \multirow[t]{2}{*}{ Size } & $0.624^{\text {*** }}$ & $0.551^{\text {*** }}$ \\
\hline & $(32.67)$ & $(33.07)$ \\
\hline \multirow[t]{2}{*}{ Leverage } & $-0.469^{* * *}$ & $-0.422^{* * *}$ \\
\hline & $(-5.71)$ & $(-5.89)$ \\
\hline \multirow[t]{2}{*}{ TV } & -0.005 & 0.001 \\
\hline & $(-1.76)$ & $(0.39)$ \\
\hline \multirow[t]{2}{*}{ Boardsize } & 0.013 & $0.015^{*}$ \\
\hline & $(1.78)$ & $(2.36)$ \\
\hline \multirow{2}{*}{ Compensation } & $0.204^{* * *}$ & $0.162^{* * *}$ \\
\hline & $(10.07)$ & $(9.19)$ \\
\hline $\mathrm{RD}$ & $4.075^{* * *}$ & $3.141^{* * *}$ \\
\hline
\end{tabular}




\begin{tabular}{|c|c|c|}
\hline & $(7.27)$ & $(6.45)$ \\
\hline Year & Control & Control \\
\hline Industry & Control & Control \\
\hline Cons & $-13.623^{* * *}$ & $-12.704^{* * *}$ \\
\hline$N$ & $(-30.42)$ & $(-32.49)$ \\
\hline r2 within & 10696 & 10558 \\
\hline r2 overall & 0.181 & 0.183 \\
\hline
\end{tabular}

(Note: (1) The value in brackets is $t$ value; (2) ${ }^{* * *},{ }^{* *}$ and * respectively represent the significance level of $1 \%, 5 \%$ and $10 \%$; (3) There are many dummy variables in industry and year, and the regression results are not listed. (the same below))

\section{Further Inspection}

\section{Star Analysts and Non-star Analysts}

To verify the difference between non-recurring profit and loss caused by different analysts' attention and the information content index of non-recurring profit and loss, this paper first classifies the number of analysts tracking by various companies according to whether they are star analysts, and then uses the number of analysts tracking by various types of analysts and the ratio of non-recurring profit and loss to net profit for regression analysis. This is named as models (3) and (4) respectively, the regression results are listed in Table 4. The results show that the regression coefficients of the number of star analysts and the number of non-star analysts are negative, and the regression coefficients are significant at the level of $1 \%$, indicating that star analysts and non-star analysts will carry out the indicator of non-recurring gains and losses. It shows that both star analysts and non-star analysts will pay attention to the indicator of nonrecurring gains and losses, and will recognize the information content transmitted by the indicator. If the indicator is too high, the analyst will lose the need to track companies. In addition, the absolute value of the regression coefficient of non-star analysts is greater, it shows that this indicator has a greater impact on the number of non-star analysts tracking, and non-star analysts pay more attention to this indicator. The reason may be that the indicator is directly available in the report and has a high information content, so it is widely used by various analysts including star analysts and non-star analysts. Comparing with non-star analysts, star analysts may pay more attention to the analysis index when analyzing the enterprise, so the index has less influence on the number of analysts tracking.

Cov_STAR_log $=\gamma_{1}$ EI_Per $+\gamma_{2}$ ROA $+\gamma_{3}$ TQ $+\gamma_{4}$ Growth $+\gamma_{5}$ Top $1+\gamma_{6}$ SOE $+\gamma_{7}$ Size $+\gamma_{8}$ Leverage

$+\gamma_{9} \overline{\mathrm{TV}}+\gamma_{10}$ Boardsize $+\bar{\gamma}_{11}$ Compensation $+\gamma_{12} \mathrm{RD}+\gamma_{13}$ Year $+\gamma_{14}$ Ind $+\varepsilon$

Cov_NonSTAR_log $==\gamma_{1}$ EI_Per $+\gamma_{2}$ ROA $+\gamma_{3}$ TQ $+\gamma_{4}$ Growth $+\gamma_{5}$ Top $1+\gamma_{6}$ SOE $+\gamma_{7}$ Size

$+\gamma_{8}$ Leverage $+\gamma_{9} \mathrm{TV}+\gamma_{10}$ Boardsize $+\gamma_{11}$ Compensation $+\gamma_{12} \mathrm{RD}+\gamma_{13}$ Year $+\gamma_{14}$ Ind $+\varepsilon$

TABLE 4

REGRESSION RESULTS OF STAR ANALYSTS AND NON-STAR ANALYSTS

\begin{tabular}{|c|c|c|}
\hline \multirow{2}{*}{ Model Variables } & $(3)$ & $(4)$ \\
\cline { 2 - 3 } & Cov_STAR_log & Cov_NonSTAR_log \\
\hline EI_Per & $-0.323^{* * *}$ & $-0.420^{* * *}$ \\
\hline ROA & $(-11.35)$ & $(-13.84)$ \\
\hline & $4.477^{* * *}$ & $6.336^{* * *}$ \\
\hline TQ & $(18.92)$ & $(24.58)$ \\
\hline & $0.086^{* * *}$ & $0.106^{* * *}$ \\
\hline Growth & $(13.27)$ & $(15.02)$ \\
\hline & -0.040 & 0.024 \\
\hline
\end{tabular}




\begin{tabular}{|c|c|c|}
\hline Top1 & $-0.150^{*}$ & -0.136 \\
\hline & $(-2.50)$ & $(-1.89)$ \\
\hline SOE & $-0.134^{* * *}$ & $-0.213^{* * *}$ \\
\hline & $(-6.46)$ & $(-8.30)$ \\
\hline Size & $0.333^{* * *}$ & $(31.71)$ \\
\hline & $(28.26)$ & $-0.352^{* * *}$ \\
\hline Leverage & $-0.159^{* *}$ & $(-5.93)$ \\
\hline TV & $(-3.03)$ & 0.001 \\
\hline & $-0.006^{* *}$ & $(0.51)$ \\
\hline Boardsize & $(-2.74)$ & 0.010 \\
\hline & -0.000 & $(1.91)$ \\
\hline Compensation & $(-0.05)$ & $0.138^{* * *}$ \\
\hline & $0.089^{* * *}$ & $(9.46)$ \\
\hline RD & $(6.97)$ & $3.341^{* * *}$ \\
\hline & 0.687 & $(8.23)$ \\
\hline Year & $(1.90)$ & Control \\
\hline Industry & Control & Control \\
\hline Cons & Control & $-9.761^{* * *}$ \\
\hline N & $-7.806^{* * *}$ & $(-30.22)$ \\
\hline r2 within & $(-28.60)$ & 10696 \\
\hline r2 overall & 10696 & 0.199 \\
\hline & 0.113 & 0.442 \\
\hline
\end{tabular}

\section{Overseas Background Analysts and Local Analysts}

In order to verify the attention of different analysts caused by non-recurring profit and loss and how they identify the information content of the indicator of non-recurring profit and loss, the paper classifies the number of analysts tracked by each company according to whether they are overseas background analysts, that is, they are divided into overseas background analysts and local analysts, and then the number of analysts tracked by different types of analysts and non-recurring are used respectively The proportion of profit and loss in net profit is analyzed by regression, namely model (5) and (6). The regression results are shown in Table 5. The results show that the regression coefficient between the number of overseas background analysts and the number of local analysts is negative, and it is significant at the level of $1 \%$, which indicates that both overseas background analysts and local analysts will pay attention to the indicator of non-recurring profit and loss, and both will recognize the information content conveyed by the indicator. If the index is too high, analysts will lose interest in the company. It is necessary to follow up. In addition, the absolute value of the regression coefficient of local analysts is larger, which indicates that the index has a higher impact on the number of local analysts to track, and the local analysts pay more attention to this indicator. The reason may be that the indicator is directly available in the statements and has high information content, so it is widely used by analysts, including overseas background analysts and local analysts. However, comparing with overseas background analysts, local analysts have a better understanding of the enterprise and can use this indicator to make a reasonable judgment on the company's situation. Therefore, when analyzing an enterprise, it may not be as focused on analysis indicators as analysts from overseas backgrounds. The index has a greater impact on its tracking number.

Cov_Foreign_log $=\gamma_{1}$ EI_Per $+\gamma_{2} \mathrm{ROA}+\gamma_{3} \mathrm{TQ}+\gamma_{4}$ Growth $+\gamma_{5}$ Top $1+\gamma_{6} \mathrm{SOE}+\gamma_{7} \mathrm{Size}+\gamma_{8}$ Leverage $+\gamma_{9} \mathrm{TV}+$ $\gamma_{10}$ Boardsize $+\gamma_{11}$ Compensation $+\gamma_{12} \mathrm{RD}+\gamma_{13}$ Year $+\gamma_{14}$ Ind $+\varepsilon$

Cov_Local_log $=\gamma_{1}$ EI_Per $+\gamma_{2}$ ROA $+\gamma_{3}$ TQ $+\gamma_{4}$ Growth $+\gamma_{5}$ Top $1+\gamma_{6}$ SOE $+\gamma_{7}$ Size $+\gamma_{8}$ Leverage $+\gamma_{9} \mathrm{TV}+$ $\gamma_{10}$ Board size $+\gamma_{11}$ Compensation $+\gamma_{12}$ RD $+\gamma_{13}$ Year $+\gamma_{14}$ Ind $+\varepsilon$ 


\section{TABLE 5}

\section{REGRESSION RESULTS OF OVERSEAS BACKGROUND ANALYSTS AND LOCAL ANALYSTS}

\begin{tabular}{|c|c|c|}
\hline \multirow{2}{*}{ Model Variable } & $(5)$ & (6) \\
\hline & Cov Foreign log & Cov local log \\
\hline \multirow[t]{2}{*}{ EI_Per } & $-0.124^{* * *}$ & $-0.427^{* * *}$ \\
\hline & $(-7.05)$ & $(-14.24)$ \\
\hline \multirow[t]{2}{*}{ ROA } & $1.083^{* * *}$ & $6.556^{* * *}$ \\
\hline & $(7.48)$ & $(25.68)$ \\
\hline \multirow[t]{2}{*}{ TQ } & $0.031^{* * *}$ & $0.112^{* * *}$ \\
\hline & $(7.93)$ & $(16.10)$ \\
\hline \multirow[t]{2}{*}{ Growth } & -0.027 & 0.016 \\
\hline & $(-1.91)$ & $(0.69)$ \\
\hline \multirow[t]{2}{*}{ Top1 } & -0.010 & -0.134 \\
\hline & $(-0.27)$ & $(-1.84)$ \\
\hline \multirow[t]{2}{*}{ SOE } & $-0.046^{* * *}$ & $-0.225^{* * *}$ \\
\hline & $(-3.81)$ & $(-8.69)$ \\
\hline \multirow[t]{2}{*}{ Size } & $0.104^{* * *}$ & $0.467^{* * *}$ \\
\hline & $(14.81)$ & $(33.80)$ \\
\hline \multirow[t]{2}{*}{ Leverage } & -0.016 & $-0.373^{* * *}$ \\
\hline & $(-0.51)$ & $(-6.31)$ \\
\hline \multirow[t]{2}{*}{ TV } & 0.001 & 0.000 \\
\hline & $(0.86)$ & $(0.17)$ \\
\hline \multirow[t]{2}{*}{ Boardsize } & -0.002 & $0.011^{*}$ \\
\hline & $(-0.82)$ & $(2.14)$ \\
\hline \multirow[t]{2}{*}{ Compensation } & $0.030^{* * *}$ & $0.143^{* * *}$ \\
\hline & $(3.94)$ & $(9.82)$ \\
\hline \multirow[t]{2}{*}{$\mathrm{RD}$} & 0.211 & $2.897^{* * *}$ \\
\hline & $(0.97)$ & $(7.18)$ \\
\hline Year & Control & Control \\
\hline Industry & Control & Control \\
\hline \multirow[t]{2}{*}{ Cons } & $-2.587^{* * *}$ & $-10.357^{* * *}$ \\
\hline & $(-15.98)$ & $(-31.95)$ \\
\hline$N$ & 10696 & 10696 \\
\hline r2 within & 0.040 & 0.196 \\
\hline r2 overall & 0.216 & 0.460 \\
\hline
\end{tabular}

Analysis on the Accuracy of Analysts' Tracking Forecast

It has been verified that analysts including star analysts and non-star analysts, overseas background analysts and local analysts will pay attention to the ratio of non-recurring profit and loss to net profit, and the degree of attention is slightly different. In order to further verify the information content of the ratio of non-recurring profit and loss to net profit, this paper replaces the dependent variable with analyst forecast accuracy. That is the absolute value of the difference between an analyst's forecast EPS of a certain stock in a certain year minus the actual EPS of the stock in that year, and then dividing by the absolute value of the actual EPS of the stock, the index standard accurately describes the analyst's forecast deviation.

In order to control the influence of year and industry effect on the model, this paper first controls the year effect, and then control the industry effect. Finally, this paper controls the year and industry effect at the same time, it is named as model (7). The regression results are shown in Table 6. The results show that the coefficient before the proportion of non-recurring profit and loss in net profit is positive, and with the control of industry and year, the significance and size of coefficient increase, and the significance 
level of control industry and after year is $1 \%$. It proves that the greater the proportion of non-recurring profit and loss in net profit, the greater the deviation of analysts' forecast, the lower the analyst forecast accuracy.

Facc $=\delta_{1}$ EI_Per $+\delta_{2}$ ROA $+\delta_{3} \mathrm{TQ}+\delta_{4}$ Growth $+\delta_{5}$ Top $1+\delta_{6} \mathrm{SOE}+\delta_{7}$ Size $+\delta_{8}$ Leverage $+\delta_{9} \mathrm{TV}+\delta_{10}$ Boardsize $+\delta_{11}$ Compensation $+\delta_{12} \mathrm{RD}+\delta_{13}$ Year $+\delta_{14} \mathrm{Ind}+\varepsilon$

TABLE 6

NON-RECURRING GAINS AND LOSSES AND ANALYST TRACKING FORECAST ACCURACY

\begin{tabular}{|c|c|c|c|}
\hline \multirow{2}{*}{ Model Variable } & (7) & (7) & (7) \\
\hline & Facc & Facc & Facc \\
\hline \multirow[t]{2}{*}{ EI_Per } & $2.515^{* *}$ & $2.823^{* * *}$ & $2.848^{* * *}$ \\
\hline & $(3.13)$ & $(3.55)$ & $(3.58)$ \\
\hline \multirow[t]{2}{*}{ ROA } & $-21.458^{* * *}$ & -9.714 & $-14.062^{*}$ \\
\hline & $(-3.55)$ & $(-1.64)$ & $(-2.31)$ \\
\hline \multirow[t]{2}{*}{ TQ } & $0.610^{* * *}$ & 0.219 & $0.408^{*}$ \\
\hline & $(3.78)$ & $(1.49)$ & $(2.43)$ \\
\hline \multirow[t]{2}{*}{ Growth } & -0.173 & 0.128 & -0.318 \\
\hline & $(-0.26)$ & $(0.20)$ & $(-0.48)$ \\
\hline \multirow[t]{2}{*}{ Top1 } & $-3.394^{* *}$ & -1.952 & -2.044 \\
\hline & $(-2.81)$ & $(-1.60)$ & $(-1.68)$ \\
\hline \multirow[t]{2}{*}{ SOE } & -0.066 & -0.101 & -0.214 \\
\hline & $(-0.17)$ & $(-0.25)$ & $(-0.53)$ \\
\hline \multirow[t]{2}{*}{ Size } & $1.229^{* * * *}$ & $0.622^{* *}$ & $0.924^{* * *}$ \\
\hline & $(5.01)$ & $(2.65)$ & $(3.64)$ \\
\hline \multirow[t]{2}{*}{ Leverage } & -1.642 & 0.047 & -0.170 \\
\hline & $(-1.38)$ & $(0.04)$ & $(-0.14)$ \\
\hline \multirow[t]{2}{*}{ TV } & -0.003 & -0.071 & -0.015 \\
\hline & $(-0.06)$ & $(-1.39)$ & $(-0.26)$ \\
\hline \multirow[t]{2}{*}{ Boardsize } & 0.147 & 0.168 & 0.127 \\
\hline & $(1.48)$ & $(1.69)$ & $(1.26)$ \\
\hline \multirow[t]{2}{*}{ Compensation } & $-2.012^{* * *}$ & $-1.845^{* * *}$ & $-1.705^{* * *}$ \\
\hline & $(-7.24)$ & $(-6.61)$ & $(-6.03)$ \\
\hline \multirow[t]{2}{*}{$\mathrm{RD}$} & 1.097 & 0.257 & 6.113 \\
\hline & $(0.16)$ & $(0.03)$ & $(0.71)$ \\
\hline Year & Control & Not Control & Control \\
\hline Industry & Not Control & Control & Control \\
\hline \multirow[t]{2}{*}{ Cons } & 4.140 & $13.860^{* *}$ & 5.167 \\
\hline & $(0.77)$ & $(2.64)$ & $(0.87)$ \\
\hline$N$ & 9683 & 9683 & 9683 \\
\hline r2 within & 0.011 & 0.009 & 0.010 \\
\hline r2 overall & 0.014 & 0.073 & 0.075 \\
\hline
\end{tabular}

Analysis on the Optimism Deviation of Analyst Tracking Forecast

In order to further verify the information content of the indicator proportion of non-recurring profit and loss to net profit, this paper replaces the dependent variable with the optimistic deviation of analyst tracking forecast. The optimistic deviation of analyst tracking forecast is that the EPS of an analysts' forecast of a certain stock in a certain year minus the actual EPS of the current year divided by the closing price of the stock before the forecast trading day. The degree of optimism (pessimism) between the 
forecasting situation and the actual situation is analyzed. This indicator depicts the degree of optimism (pessimism) of analysts' forecasts compared with the actual situation in the current year. In order to control the influence of year and industry effect on the model, the paper first controls the year effect, then controlling the industry effect. Finally, this paper controls the year and industry effect at the same time, it is named as model (8). The regression results are shown in Table 7. The results show that the coefficient before the ratio of non-recurring profit and loss to net profit is negative, and with the control of industry and year, the significance and absolute value of coefficient increase, and the significance level of control industry and year is $1 \%$, which proves that the larger the proportion of non-recurring profit and loss in net profit, the smaller the optimistic deviation of analysts' forecast. That is to say, the less optimistic their forecast is. This result shows that if analysts find that the company has non-recurring profit and loss, they will hold a more pessimistic attitude towards enterprise forecasting. It can be seen that the index has a great impact on the analysts' forecast, so it will also greatly affect the willingness and enthusiasm of analysts' tracking. The result further illustrates the impact of non-recurring profit and loss on the number of analysts' forecast reports and the impact of the number of analysts tracking.

Fopt $=\delta_{1}$ EI_Per $+\delta_{2} \mathrm{ROA}+\delta_{3} \mathrm{TQ}+\delta_{4}$ Growth $+\delta_{5}$ Top $1+\delta_{6} \mathrm{SOE}+\delta_{7}$ Size $+\delta_{8}$ Leverage $+\delta_{9} \mathrm{TV}+\delta_{10}$ Boardsize + $\delta_{11}$ Compensation $+\delta_{12} \mathrm{RD}+\delta_{13}$ Year $+\delta_{14} \mathrm{Ind}+\varepsilon$

TABLE 7

NON-RECURRING PROFIT AND LOSS AND OPTIMISM DEVIATION FROM ANALYST TRACKING FORECAST

\begin{tabular}{|c|c|c|c|}
\hline \multirow{2}{*}{ Model Variable } & $(8)$ & $(8)$ & $(8)$ \\
\hline & Fopt & Fopt & Fopt \\
\hline \multirow[t]{2}{*}{ EI_Per } & $-0.016^{* * *}$ & $-0.017^{* * *}$ & $-0.016^{* * *}$ \\
\hline & $(-12.36)$ & $(-12.85)$ & $(-12.68)$ \\
\hline \multirow[t]{2}{*}{ ROA } & $-0.161^{* * * *}$ & $-0.137^{* * *}$ & $-0.152^{* * *}$ \\
\hline & $(-15.71)$ & $(-13.50)$ & $(-14.66)$ \\
\hline \multirow[t]{2}{*}{ TQ } & 0.000 & $-0.000^{*}$ & 0.000 \\
\hline & $(1.56)$ & $(-2.00)$ & $(0.75)$ \\
\hline \multirow[t]{2}{*}{ Growth } & $-0.008^{* * *}$ & $-0.006^{* * *}$ & $-0.008^{* * *}$ \\
\hline & $(-8.18)$ & $(-6.35)$ & $(-7.98)$ \\
\hline \multirow[t]{2}{*}{ Top1 } & -0.002 & -0.003 & -0.003 \\
\hline & $(-0.83)$ & $(-1.22)$ & $(-1.42)$ \\
\hline \multirow[t]{2}{*}{ SOE } & -0.000 & 0.000 & -0.000 \\
\hline & $(-0.38)$ & $(0.46)$ & $(-0.04)$ \\
\hline \multirow[t]{2}{*}{ Size } & 0.000 & $-0.001^{* * *}$ & -0.000 \\
\hline & $(0.68)$ & $(-3.40)$ & $(-0.54)$ \\
\hline \multirow[t]{2}{*}{ Leverage } & $0.009^{* * *}$ & $0.011^{* * *}$ & $0.010^{* * *}$ \\
\hline & $(4.27)$ & $(4.81)$ & $(4.75)$ \\
\hline \multirow[t]{2}{*}{ TV } & $-0.000^{* * *}$ & $-0.001^{* * *}$ & $-0.000^{* *}$ \\
\hline & $(-3.57)$ & $(-6.29)$ & $(-3.27)$ \\
\hline \multirow[t]{2}{*}{ Boardsize } & 0.000 & 0.000 & 0.000 \\
\hline & $(0.45)$ & $(1.51)$ & $(0.62)$ \\
\hline \multirow[t]{2}{*}{ Compensation } & $-0.002^{* * *}$ & $-0.002^{* * *}$ & $-0.002^{* *}$ \\
\hline & $(-4.03)$ & $(-4.00)$ & $(-3.04)$ \\
\hline \multirow[t]{2}{*}{ RD } & 0.025 & -0.015 & 0.008 \\
\hline & $(1.94)$ & $(-1.00)$ & $(0.50)$ \\
\hline Year & Control & Not Control & Control \\
\hline Industry & Not Control & Control & Control \\
\hline Cons & $0.039^{* * *}$ & $0.092^{* * *}$ & $0.053^{\text {*** }}$ \\
\hline
\end{tabular}




\begin{tabular}{|c|c|c|c|}
\hline & $(4.00)$ & $(9.40)$ & $(4.87)$ \\
\hline$N$ & 9667 & 9667 & 9667 \\
\hline r2 within & 0.061 & 0.049 & 0.062 \\
\hline r2 overall & 0.091 & 0.105 & 0.118 \\
\hline
\end{tabular}

Analysis of Analyst Tracking Forecast Interval

In order to further verify the information content of the ratio of non-recurring profit and loss to net profit, the paper replaced the dependent variable with the analyst tracking forecast interval for regression. The analyst tracking forecast interval is the difference between the forecast time of a certain analyst in a certain year and the date of annual financial report.

$\operatorname{lnHorizon}=\delta_{1}$ EI_Per $+\delta_{2} \mathrm{ROA}+\delta_{3} \mathrm{TQ}+\delta_{4}$ Growth $+\delta_{5} \mathrm{Top} 1+\delta_{6} \mathrm{SOE}+\delta_{7} \mathrm{Size}+\delta_{8}$ Leverage $+\delta_{9} \mathrm{TV}+\delta_{10}$ Boardsize $+\delta_{11}$ Compensation $+\delta_{12} \mathrm{RD}+\delta_{13}$ Year $+\delta_{14}$ Ind $+\varepsilon$

TABLE 8

NON-RECURRING GAINS AND LOSSES AND ANALYST TRACKING FORECAST INTERVAL REGRESSION RESULTS

\begin{tabular}{|c|c|c|c|}
\hline \multirow{2}{*}{ Model Variable } & (9) & (9) & (9) \\
\hline & lnHorizon & lnHorizon & lnHorizon \\
\hline \multirow[t]{2}{*}{ EI_Per } & $0.135^{* * *}$ & $0.144^{* * *}$ & $0.132^{* * *}$ \\
\hline & $(7.00)$ & $(7.28)$ & $(6.80)$ \\
\hline \multirow[t]{2}{*}{$\mathrm{ROA}$} & $-2.175^{* * *}$ & $-2.797^{* * *}$ & $-2.211^{* * *}$ \\
\hline & $(-13.98)$ & $(-17.92)$ & $(-14.02)$ \\
\hline \multirow[t]{2}{*}{ TQ } & $-0.053^{* * *}$ & $-0.048^{* * *}$ & $-0.053^{* * *}$ \\
\hline & $(-12.63)$ & $(-12.71)$ & $(-12.33)$ \\
\hline \multirow[t]{2}{*}{ Growth } & $-0.122^{* * *}$ & $-0.111^{* * *}$ & $-0.125^{* * *}$ \\
\hline & $(-7.92)$ & $(-7.15)$ & $(-8.02)$ \\
\hline \multirow[t]{2}{*}{ Top1 } & 0.053 & 0.030 & 0.059 \\
\hline & $(1.44)$ & $(0.79)$ & $(1.58)$ \\
\hline \multirow[t]{2}{*}{ SOE } & $0.063^{* * *}$ & $0.030^{*}$ & $0.059^{* * * *}$ \\
\hline & $(5.17)$ & $(2.33)$ & $(4.69)$ \\
\hline \multirow[t]{2}{*}{ Size } & $-0.101^{* * *}$ & $-0.081^{* * *}$ & $-0.108^{* * *}$ \\
\hline & $(-14.08)$ & $(-11.73)$ & $(-14.52)$ \\
\hline \multirow[t]{2}{*}{ Leverage } & -0.001 & $-0.102^{* *}$ & -0.017 \\
\hline & $(-0.04)$ & $(-2.98)$ & $(-0.50)$ \\
\hline \multirow[t]{2}{*}{$\mathrm{TV}$} & $0.005^{* * *}$ & 0.001 & $0.005^{* * *}$ \\
\hline & (3.74) & $(0.83)$ & (3.51) \\
\hline \multirow[t]{2}{*}{ Boardsize } & -0.002 & $-0.010^{* *}$ & -0.002 \\
\hline & $(-0.78)$ & $(-3.24)$ & $(-0.60)$ \\
\hline \multirow[t]{2}{*}{ Compensation } & $-0.019^{*}$ & 0.013 & $-0.020^{*}$ \\
\hline & $(-2.44)$ & $(1.61)$ & $(-2.42)$ \\
\hline \multirow[t]{2}{*}{$\mathrm{RD}$} & $-0.830^{* * *}$ & 0.131 & $-0.877^{* * *}$ \\
\hline & $(-4.17)$ & $(0.56)$ & $(-3.72)$ \\
\hline Year & Control & Not Control & Control \\
\hline Industry & Not Control & Control & Control \\
\hline \multirow[t]{2}{*}{ Cons } & $7.465^{* * *}$ & $6.945^{* * *}$ & $7.628^{* * *}$ \\
\hline & $(48.98)$ & $(45.15)$ & $(44.41)$ \\
\hline$N$ & 10696 & 10696 & 10696 \\
\hline r2 within & 0.106 & 0.062 & 0.106 \\
\hline r2 overall & 0.170 & 0.159 & 0.193 \\
\hline
\end{tabular}




\section{Robustness Tests}

In order to verify the sensitivity of the above main test and further test results, this paper replaces the ratio index of non-recurring profit and loss and net profit with the logarithm of absolute value of nonrecurring profit and loss for robustness test. Regressing the main test and three other indexes, which include the accuracy of analyst tracking forecast, the optimistic deviation of analyst tracking forecast and the interval of analyst tracking forecast respectively. The coefficient sign and significance level of the results still pass these tests, which shows that the research results in this paper have strong robustness.

\section{TABLE 9}

\section{ROBUSTNESS TEST (1)}

\begin{tabular}{|c|c|c|}
\hline \multirow{2}{*}{ Model Variable } & (1) & (2) \\
\hline & Cov Report log & Cov Num log \\
\hline \multirow[t]{2}{*}{ lnAbsfeijing } & $-0.049^{* * *}$ & $-0.044^{* * *}$ \\
\hline & $(-7.97)$ & $(-8.23)$ \\
\hline \multirow[t]{2}{*}{ ROA } & $9.989^{* * *}$ & $8.218^{* * *}$ \\
\hline & $(28.07)$ & $(26.60)$ \\
\hline \multirow[t]{2}{*}{ TQ } & $0.153^{* * *}$ & $0.136^{* * *}$ \\
\hline & $(15.70)$ & $(16.08)$ \\
\hline \multirow[t]{2}{*}{ Growth } & $0.087^{* *}$ & 0.018 \\
\hline & $(2.65)$ & $(0.63)$ \\
\hline \multirow[t]{2}{*}{ Top1 } & -0.115 & -0.105 \\
\hline & $(-1.13)$ & $(-1.18)$ \\
\hline \multirow[t]{2}{*}{ SOE } & $-0.350^{* * *}$ & $-0.291^{* * *}$ \\
\hline & $(-9.66)$ & $(-9.17)$ \\
\hline \multirow[t]{2}{*}{ Size } & $0.667^{* * *}$ & $0.589^{* * *}$ \\
\hline & $(33.19)$ & $(33.62)$ \\
\hline \multirow[t]{2}{*}{ Leverage } & $-0.467^{* * *}$ & $-0.423^{* * *}$ \\
\hline & $(-5.64)$ & $(-5.85)$ \\
\hline \multirow[t]{2}{*}{ TV } & -0.006 & 0.001 \\
\hline & $(-1.86)$ & $(0.28)$ \\
\hline \multirow[t]{2}{*}{ Boardsize } & 0.014 & $0.016^{*}$ \\
\hline & $(1.93)$ & $(2.50)$ \\
\hline \multirow[t]{2}{*}{ Compensation } & $0.215^{* * *}$ & $0.172^{* * *}$ \\
\hline & $(10.55)$ & $(9.70)$ \\
\hline \multirow[t]{2}{*}{$\mathrm{RD}$} & $4.023^{* * *}$ & $3.099^{* * *}$ \\
\hline & $(7.13)$ & $(6.31)$ \\
\hline Year & Control & Control \\
\hline Industry & Control & Control \\
\hline \multirow[t]{2}{*}{ Cons } & $-14.106^{* * *}$ & $-13.144^{* * *}$ \\
\hline & $(-31.13)$ & $(-33.23)$ \\
\hline$N$ & 10696 & 10558 \\
\hline r2 within & 0.178 & 0.177 \\
\hline r2 overall & 0.447 & 0.434 \\
\hline
\end{tabular}


TABLE 10

ROBUSTNESS TEST (2)

\begin{tabular}{|c|c|c|c|}
\hline Model Variable & (7) & (8) & (9) \\
\hline & Facc & Fopt & lnHorizon \\
\hline \multirow[t]{2}{*}{$\ln A b s f e i j i n g$} & $0.309^{* *}$ & $-0.001^{* *}$ & $0.012^{* * *}$ \\
\hline & $(2.75)$ & $(-2.78)$ & $(4.19)$ \\
\hline \multirow[t]{2}{*}{ ROA } & $-19.603^{* * *}$ & $-0.126^{* * *}$ & $-2.431^{* * *}$ \\
\hline & $(-3.30)$ & $(-12.26)$ & $(-15.55)$ \\
\hline \multirow[t]{2}{*}{ TQ } & $0.396^{*}$ & 0.000 & $-0.054^{* * *}$ \\
\hline & $(2.35)$ & $(0.90)$ & $(-12.44)$ \\
\hline \multirow[t]{2}{*}{ Growth } & -0.304 & $-0.008^{* * *}$ & $-0.125^{* * *}$ \\
\hline & $(-0.46)$ & $(-7.53)$ & $(-8.03)$ \\
\hline \multirow[t]{2}{*}{ Top1 } & -2.136 & -0.002 & 0.052 \\
\hline & $(-1.75)$ & $(-0.89)$ & $(1.38)$ \\
\hline \multirow[t]{2}{*}{ SOE } & -0.175 & -0.001 & $0.062^{* * *}$ \\
\hline & $(-0.43)$ & $(-0.64)$ & $(4.85)$ \\
\hline \multirow[t]{2}{*}{ Size } & $0.627^{*}$ & 0.000 & $-0.119^{* * *}$ \\
\hline & $(2.27)$ & $(0.46)$ & $(-15.01)$ \\
\hline \multirow[t]{2}{*}{ Leverage } & -0.130 & $0.010^{* * *}$ & -0.016 \\
\hline & $(-0.11)$ & $(4.38)$ & $(-0.47)$ \\
\hline \multirow[t]{2}{*}{ TV } & -0.010 & $-0.000^{* * *}$ & $0.005^{* * *}$ \\
\hline & $(-0.18)$ & $(-3.32)$ & $(3.59)$ \\
\hline \multirow[t]{2}{*}{ Boardsize } & 0.124 & 0.000 & -0.002 \\
\hline & $(1.24)$ & $(0.86)$ & $(-0.67)$ \\
\hline \multirow[t]{2}{*}{ Compensation } & $-1.738^{* * *}$ & $-0.001^{* *}$ & $-0.022^{* *}$ \\
\hline & $(-6.14)$ & $(-2.74)$ & $(-2.66)$ \\
\hline \multirow[t]{2}{*}{$\mathrm{RD}$} & 5.553 & 0.007 & $-0.884^{* * *}$ \\
\hline & $(0.65)$ & $(0.46)$ & $(-3.74)$ \\
\hline Year & Control & Control & Control \\
\hline Industry & Control & Control & Control \\
\hline \multirow[t]{2}{*}{ Cons } & 7.978 & $0.043^{* * *}$ & $7.742^{* * *}$ \\
\hline & $(1.34)$ & $(3.92)$ & $(44.83)$ \\
\hline$N$ & 9683 & 9667 & 10696 \\
\hline r2 within & 0.010 & 0.045 & 0.106 \\
\hline r2 overall & 0.075 & 0.106 & 0.190 \\
\hline
\end{tabular}

\section{CONCLUSION}

Many scholars have studied which type of factors affect analyst behavior. Taking A-share listed companies from 2009 to 2015 as samples, this paper studies the non-recurring profit and loss. This paper uses a unique indicator in China to do research, results finds that the proportion of non-recurring profit and loss affects analyst behavior. The larger non-recurring profit and loss accounts for the ratio, the greater the enterprise profit structure, the worse the persistence of earnings, the less analysts will track these companies. But analysts have heterogeneity, such as star analyst and non- star analyst in financial report, there is a difference between private information acquisition, overseas background analysts and local analysts may exist big differences. Therefore, according to analyst's heterogeneity grouping study, the paper found: (1) the number of follow-up analysis and reports of corporate analysts with a large proportion of non-recurring gains and losses is relatively small and negatively correlated. It is further 
found that not only star analysts and non-star analysts, but also local analysts and overseas background analysts can identify the information content of non-recurring gains and losses; (2) For enterprises with large proportion of non-recurring profits and losses, the analysts' forecast is more inaccurate, the optimism deviation is smaller, and the forecast range is larger, and the results remain unchanged after controlling the enterprise and the industry; (3) This paper deepens the understanding of the impact of nonrecurring gains and losses on the capital market. It enriches the literature on non-recurring gains and losses and analyst behavior, which is of great significance to both theory and practice. This paper also answered another question: Which type of factors will analysts consider when choosing stock tracking? We find that analysts will consider enterprise operating conditions, earnings conditions, especially whether the earnings are sustainable and other factors are considered by analysts. This paper is of great significance for investors to choose stocks in practice.

\section{REFERENCES}

Cai, L., Zheng, Q., \& Cai, C. (2018). Can Shared Auditors Reduce Analyst Forecasting Bias? - Empirical Evidence from China's A-share Listed Companies. Audit Research, (01), 86-93.

Deng, N. (2016). Research on Non-recurring Profits and Losses of Listed Companies in 2015 and Problems. Securities Market Guide, (11), 64-68.

Ding, F., \& Wen, S. (2016). Research on Social Responsibility Information Disclosure and Accuracy of Analyst Cash Flow Prediction. Finance \& Accounting Newsletter, (30), 122-124.

Dong, Y., Ding, B., \& Liu, Y. (2015). Analysis of Non-recurring Profit and Loss Information of Listed Companies - Based on the Study of 2012 Annual Report of the Automobile Industry. Finance \& Accounting Bulletin, (28), 29-33.

Fan, X., \& Zheng, J. (2009). Presentation of Non-Recurring Gains and Losses: Theory, Criteria and Analysis. Accounting Research, (11), 36-43.

Gong, G., \& Yu, H. (2017). Impact of Earnings forecast Information on Analysts' Earnings Forecast Correction. Accounting Monthly, (18), 30-35.

Hu, F., \& Xia, Y. (2017). Deviation of Analysts' Commercial Motivation and Earnings Forecast: Evidence from Margin Financing. Financial and Economic Research, (07), 45-56.

Hu, Y., \& Lin, W. (2005). Depth of Information Attention, Analytical Ability and Analytical Quality Investigation and Analysis of Securities Analysts in China. Financial Research, (2), 46-58.

Hu, Y., Lin, W., \& Wang, W. (2003). Information Sources, Areas of Concern and Analysis Tools of Securities Analysts. Financial Research, (12), 52-63.

Huang, J., Huang, C., \& Wei, H. (2018). Does Short Selling Mechanism Improve the Quality of Analysts' Earnings Forecast -- Empirical Evidence Based on Margin and Short Selling System. Nankai Management Review, (02), 135-148.

Jia, W., Hong, J., \& Xu, Y. (2015). Is It Valuable for Chinese Securities Analysts to Conduct Field Research? -An Empirical Study Based on the Accuracy of Earnings Prediction. Investment Research, (04), 96-113.

Jiang, D., \& Xiong, J. (2012). Non-recurring Profit and Loss, Accounting Standard Change and Earnings Management of ST Company. Nankai Management Review, (04), 151-160.

Jiang, Y., \& Wang, L. (2003). Why Non-recurring Profits and Losses Often Occur -- Evidence from the Annual Reports of Loss-making Listed Companies. Securities Market Guide, (06), 9-13.

Li, C., \& Zhang, Z. (2003). Usefulness of Accounting Earnings Index after Deducting Non-Recurring Gains and Losses. Journal of Xiamen University (Philosophy and Social Sciences Edition), (02), 114-121.

Liu, Y., \& Gao, S. (2014). Quality of Information Disclosure, Expertise of Analyst Industry and Accuracy of Forecast - Empirical Evidence from A-share Market in Shenzhen. Accounting Research, (12), 60-65.

Luo, Y., Ma, Z., \& Wang, Y. (2018). Influence of Brokers Following Overseas Listed Companies on the Accuracy of Domestic Analysts' Earnings Forecast. Financial Research, (08), 190-206. 
Meng, Y., \& Zhang, L. (2003). Discussion on Recognition and Disclosure of Non-recurring Profit and Loss. Accounting Research, (12), 14-18.

Qi, W. (2018). Audit Quality, Accounting Robustness and Analyst Earnings Forecast. Finance and Accounting Communications, (27), 28-33.

Qu, X., \& Bi, C. (2016). Accounting Information and Analysts' Information Interpretation Behavior. Accounting Research, (04), 19-26.

Sai, N. (2017). Analysis of Non-recurring Profit and Loss Information Disclosure of Listed Companies A Case Study of the Electronic Payment Industry. Finance \& Accounting Communications, (10), 32-35.

Tan, S., Cui, X. (2015). Whether the Survey of Listed Companies Can Improve the Forecast Accuracy of Analysts. World Economy, (04), 126-145.

Tan, Y. (2008). Asset Impairment Provisions, Non-Recurring Profit and loss Disclosure ControlEmpirical Evidence from China's Listed Companies. Management World, (11), 129-142.

Tang, S., \& Chen, W. (2017). Reputation Enhancement or Interest Alignment: Research on the Motivations of Field Research of Related Securities Analysts. Management World, (09), 178-179.

Tang, S., \& Chen, W. (2017). Reputation Enhancement or Interest Alignment: Research on the Motivations of Field Research of Related Securities Analysts. Management World, (09), 178-179.

Tao, R. (2018). Private Information, Timeliness and Accuracy of Analyst prediction. Shanghai Finance, (07), 19-26.

Wang, F., \& Zhang, J. (2013). The influence of Non-recurring Profit and Loss on Corporate Earnings under the Background of 2013. 06 Guidelines - Empirical Data from A-share Listed Companies. Journal of Yunnan University of Finance and Economics, (02), 154-160.

Wang, X., Li, Y., \& Xiao, M. (2017). Does Risk Disclosure in Annual Reports Contribute to Improving Analyst Prediction Accuracy? Accounting Research, (10), 37-43.

Wang, X., Li, Y., \& Xiao, M. (2017). Does Risk Disclosure in Annual Reports Contribute to Improving Analyst Prediction Accuracy? Accounting Research, (10), 37-43.

Wei, T., Lu, Z., \& Dan, H. (2007). Motivation, Means and Role of Non-recurring Profit and Loss Earnings Management - Empirical Evidence from China's Listed Companies. Management World, (01), 113-121.

Wu, Y., Jiang, J., \& Xie, N. (2016). Deviation between Corporate Governance, Information Disclosure, Investor Sentiment and Analyst Earnings Forecast. World Economy, (02), 100-119.

Xiang, Z. (2010). Research on the Correlation between Non-recurring Profit and Loss and the Quality of Financial Reports of Listed Companies. North China Electric Power University; North China Electric Power University (Beijing).

$\mathrm{Xu}, \mathrm{H}$. (2012). Impact of Non-recurring Profit and Loss on the Earnings of Listed Companies - Based on the Data of Listed companies in Shenzhen from 2008 to 2010. Monthly Journal of Finance and Accounting, (16), 46-48.

Yang, S., Jiang, F., \& Zhang, H. (2018). Typical Characteristics Analysis of Non-recurring Profits and Losses of Listed Companies -Based on Data of Listed Companies on GEM from 2014 to 2016. Finance and Accounting Communications, (34), 17-20.

Zhao, Y., \& Shang, W. (2014). Research on Real Earnings Management of Non-recurring Gains and Losses - A Case Study of T Company. Finance \& Accounting Communication, (29), 88-92.

Zhou, Q., \& Zhou, C. (2005). Study on the Influence of Non-recurring Profit and Loss on the Financial Performance of Companies Listed in Shanghai Stock Exchange. Journal of Shanghai Lixin Accounting College, (01), 1-8.

Zhou, Q., \& Zhou, C. (2005). Study on the Influence of Non-recurring Profit and Loss on the Financial Performance of Companies listed in Shanghai Stock Exchange. Journal of Shanghai Lixin Accounting College, (01), 1-8. 